\title{
Intracranial findings of Hunter syndrome
}

\author{
Ramesh S. Iyer • Paritosh C. Khanna
}

Received: 14 June 2010 / Accepted: 7 August 2010 /Published online: 18 September 2010

(C) Springer-Verlag 2010

A 13-year-old boy presented with mental retardation, progressive hearing loss and coarsened facial features. Brain MRI demonstrated punctate and oblong CSF-equivalent cystic areas within the corpus callosum, basal ganglia and periventricular white matter (Figs. 1 and 2), with surrounding hyperintensity on T2-W and FLAIR images (Fig. 1). There is mild lateral ventriculomegaly (Figs. 1 and 2). Both the boy and his mother were mutation carriers for mucopolysaccharidosis type II (MPS II, Hunter syndrome).

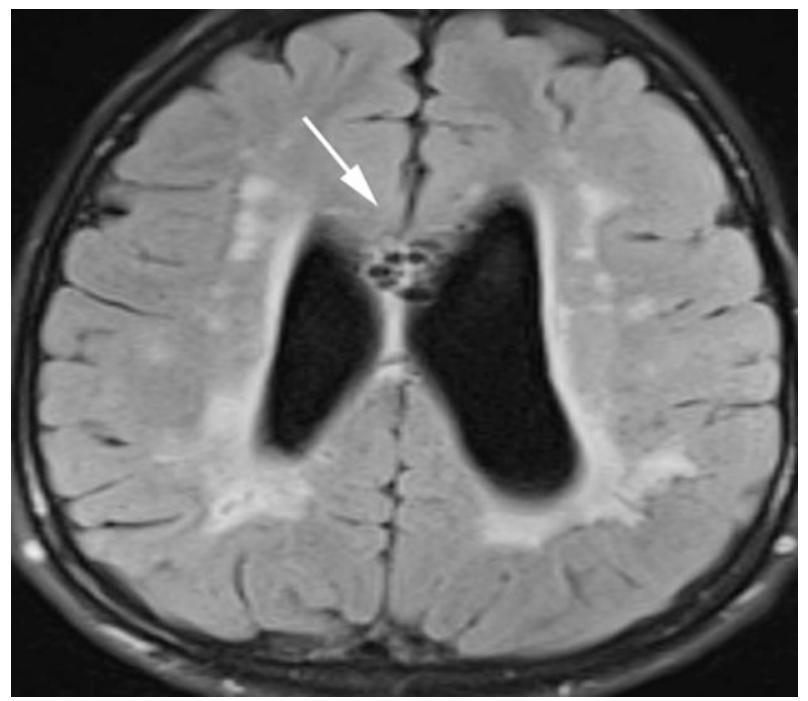

Fig. 1 Axial FLAIR image

\section{R. S. Iyer $(\bowtie)$}

Radiology,

Seattle Children's Hospital,

4800 Sand Point Way NE,

Seattle, WA 98105, USA

e-mail: rameshsiyer@gmail.com

\section{P. C. Khanna}

Pediatrics Division, Department of Radiology,

University of Washington, Seattle Children's Hospital,

Seattle, WA, USA

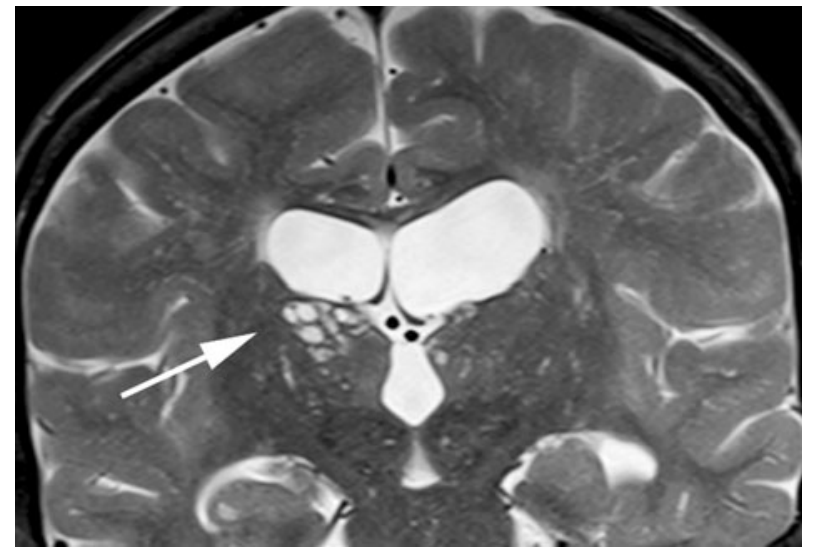

Fig. 2 Coronal T2-W image

Hunter syndrome is an $\mathrm{X}$-linked recessive lysosomal storage disorder [1]. Additional clinical associations include skeletal dysplasia, hepatosplenomegaly, recurrent respiratory infections and thickening of heart valves $[1,2]$. Characteristic intracranial findings include innumerable cysts within the periventricular white matter, corpus callosum and basal ganglia with a "cribriform," "sieve-like," or "honeycomb" appearance, from glycolipid and glycosaminoglycan buildup in Virchow-Robin perivascular spaces. Additional findings include white matter hyperintensity on T2-W and FLAIR images, hydrocephalus, and dural thickening [2].

\section{References}

1. Vedolin L, Schwartz IV, Komlos M et al (2007) Brain MRI in mucopolysaccharidosis: effect of aging and correlation with biochemical findings. Neurology 69(9):917-924

2. Finn CT, Vedolin L, Schwartz IV et al (2008) Magnetic resonance imaging findings in Hunter syndrome. Acta Paediatr 97(457):61-68 